\title{
APCI(+)FT-ICR MS Analysis of Hydrocarbons Using Isooctane as Ionizing Reagent - A Comparison with HTGC-FID, GC×GC-MS and NMR
}

\author{
Lilian V. Tose, ${ }^{a}$ Samantha R. C. Silva, ${ }^{b}$ Eliane V. Barros, ${ }^{a}$ Lindamara M. Souza, ${ }^{a}$ \\ Fernanda E. Pinto, ${ }^{a}$ Debora K. Palomino, ${ }^{b, c}$ Jair C. C. Freitas, ${ }^{b, c}$ Christopher J. Thompson, ${ }^{d}$ \\ Boniek G. Vaz, ${ }^{a, e}$ Valdemar Lacerda Jr. ${ }^{\circledR *, a}$ and Wanderson Romão ${ }^{*, a, f}$ \\ ${ }^{a}$ Laboratório de Petroleômica e Forense, Departamento de Química, \\ Universidade Federal do Espírito Santo, 29075-910 Vitória-ES, Brazil \\ ${ }^{b}$ Laboratório de Pesquisa e Desenvolvimento de Metodologias para Análise de Óleos (LabPetro), \\ Departamento de Química, Universidade Federal do Espírito Santo, 29075-910 Vitória-ES, Brazil \\ 'Laboratório de Materiais Cerâmicos e Carbonosos, Departamento de Física, \\ Universidade Federal do Espírito Santo, 29075-910 Vitória-ES, Brazil \\ ${ }^{d}$ Bruker Daltonics, 40 Manning Road, 01821 Billerica-MA, USA \\ eInstituto de Química, Universidade Federal de Goiás, 74001-970 Goiânia-GO, Brazil \\ Instituto Federal de Educação, Ciência e Tecnologia do Espírito Santo, 29106-010 Vila Velha-ES, Brazil
}

\begin{abstract}
Hydrocarbons present in saturated fractions of crude oils can be assessed by atmospheric pressure chemical ionization (APCI) using small hydrocarbons as ionizing reagents in a Fourier transform ion cyclotron resonance mass spectrometer (FT-ICR MS). In this work, five paraffin standards of different average molar mass distributions $\left(\mathrm{M}_{\mathrm{w}}\right)$ were easily ionized by APCI(+)FT-ICR MS using isooctane as the reagent gas. Data of $\mathrm{M}_{w}$, carbon number and double bond equivalent (DBE) distributions corresponding to linear and cyclic hydrocarbons (HCs) were compared to results obtained from analysis of high temperature gas chromatography with a flame ionization detector (HTGC-FID), comprehensive two-dimensional gas chromatography coupled to mass spectrometry ( $\mathrm{GC} \times \mathrm{GC}-\mathrm{MS})$ and ${ }^{1} \mathrm{H}$ and ${ }^{13} \mathrm{C}$ nuclear magnetic resonance (NMR) spectroscopy. APCI(+)FT-ICR MS data showed good agreement with those of analytical techniques. Furthermore, the ability of APCI(+) to assess $n$-paraffin, even in blends with polyaromatic hydrocarbon molecules

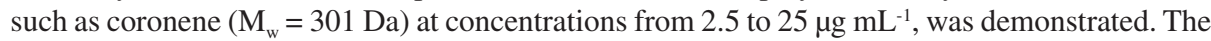
typical MS paraffin profile (containing repeating mass units of $14 \mathrm{Da}$ ) was clearly confirmed, being totally suppressed when a concentration of $25 \mu \mathrm{g} \mathrm{mL} \mathrm{m}^{-1}$ of coronene was used. This phenomenon was also evidenced in one of two saturated fractions produced using saturates, aromatics and polar (SAP) compound fractionation methodology.
\end{abstract}

Keywords: APCI(+)FT-ICR MS, paraffin, HTGC, GC×GC-MS, NMR

\section{Introduction}

Fourier transform ion cyclotron resonance mass spectrometry (FT-ICR MS) provides unsurpassed mass resolution and accuracy, enabling the complex composition of petroleum, ${ }^{1-3}$ its cuts, ${ }^{4}$ paraffin ${ }^{4-7}$ and asphaltene fractions to be analyzed on a molecular level. ${ }^{1,8-10}$ Accurate mass measurements define the unique elemental composition $\left(\mathrm{C}_{\mathrm{c}} \mathrm{H}_{\mathrm{h}} \mathrm{N}_{\mathrm{n}} \mathrm{O}_{\mathrm{o}} \mathrm{S}_{\mathrm{s}}\right)$ and double bond equivalent (DBE),

*e-mail: vljuniorqui@gmail.com; wandersonromao@gmail.com facilitating material classification by heteroatom content and the degree of aromaticity. ${ }^{11-13}$

Different methodologies have been proposed to improve the ionization of hydrocarbons (HCs) using mass spectrometry techniques. In 2004, Campbell et al. ${ }^{6}$ ionized saturated HCs using laser-induced acoustic desorption (LIAD) coupled to FT-ICR MS and assisted by chemical ionization with cyclopentadienyl cobalt radical cation $\left(\mathrm{CpCo}^{\circ}\right)$. A unique ion was produced for each alkane from $\mathrm{C}_{24} \mathrm{H}_{50}$ to $\mathrm{C}_{50} \mathrm{H}_{102}$ composed of $\left[\mathrm{R}+\mathrm{CpCo}-2 \mathrm{H}_{2}\right]^{0+}$, where R corresponds to the alkane. In 2012, Nyadong 
et al. ${ }^{7}$ presented an atmospheric pressure laser-induced acoustic desorption chemical ionization (AP/LIAD-CI) method with $\mathrm{O}_{2}$ carrier/reagent gas as a powerful new approach for the analysis of saturated HCs mixtures. In the same year, Zhou et al. ${ }^{4,5}$ reported the development of a novel technique for the characterization of HCs, where linear alkanes were selectively oxidized to ketones by ruthenium ion catalyzed oxidation (RICO). The ketones were then reduced to alcohols by lithium aluminum hydride $\left(\mathrm{LiAlH}_{4}\right)$. The monohydric alcohols $\left(\mathrm{O}_{1}\right)$ were characterized using negative-ion electrospray ionization (ESI) coupled to FT-ICR MS for identification of isoparaffins, acyclic paraffins and cyclic paraffins.

In 2012, Lorente et al. ${ }^{14}$ reported a new analytical method for HCs identification using matrix-assisted laser desorption/ ionization time-of-flight mass spectrometry (MALDI-TOF MS) with $\mathrm{AgNO}_{3}$ and based on a combination of urea adduction and thin layer or paper chromatography. However, unidentified peaks were observed in the low-mass region $(\mathrm{m} / \mathrm{z}<400)$, being likely to have arisen from interactions between the silica on the plates and the $\mathrm{AgNO}_{3}$ matrix. The method was also applied for the alkane fraction isolated by the standard urea adduction from crude oil samples.

Adapting the work of Gao et al., ${ }^{15}$ Tose et al. ${ }^{16}$ noticed that linear, cyclic and branched paraffins have their ionization favored using $\mathrm{HCs}$ with carbon numbers (CNs) between $\mathrm{C}_{5}$ and $\mathrm{C}_{8}$ as reagents in the atmospheric pressure chemical ionization (APCI) source. Among them, the isooctane provided the best results when used as a solvent/reagent. The mechanism that best explains the ionization of linear HCs is hydride abstraction, i.e., the formation of $[\mathrm{M}-\mathrm{H}]^{+}$ions..$^{15}$ This study is a continuation of the earlier work published by our group, ${ }^{16}$ where five paraffin standards of different average molar mass distribution $\left(\mathrm{M}_{\mathrm{w}}\right)$ were ionized by APCI $(+)$ FT-ICR MS using isooctane as the reagent gas. Data of $\mathrm{M}_{w}$, carbon number $(\mathrm{CN})$ and DBE distributions corresponding to linear and cyclic HCs were compared to the results obtained by other analytical methods, such as high temperature gas chromatography with a flame ionization detector (HTGC-FID), comprehensive two-dimensional gas chromatography coupled to mass spectrometry (GC $\times$ GC-MS) and ${ }^{1} \mathrm{H}$ and ${ }^{13} \mathrm{C}$ nuclear magnetic resonance (NMR) spectroscopy. Furthermore, the selectivity of the $\mathrm{APCI}(+)$ technique was also evaluated in the ionization of six commercial polyaromatic hydrocarbon $(\mathrm{PAH})$ standards and mixtures between coronene $\left(\mathrm{M}_{\mathrm{w}}=301 \mathrm{Da}\right)$ and a commercial paraffin sample. Finally, two saturated fractions produced from a saturate, aromatic and polar (SAP) compound fractionation methodology were analyzed by APCI(+)FT-ICR MS and GC $\times$ GC-MS, with a detailed comparison being carried out between the obtained results.

\section{Experimental}

\section{Reagents and samples}

Five paraffin standards, named standards P1-P5, containing carbon numbers ranging from $\mathrm{C}_{5}$ to $\mathrm{C}_{120}$ (analytical grades with purity higher than $99.5 \%$ ) were used in this study. Standards P1 and P3 were supplied by Vetec Química Fina Ltda, Brazil; standard P2 was supplied by Sigma-Aldrich Chemicals, USA; standard P4 was the result of a commercial petrochemical process; and finally, standard P5 was a reference material used for GC-FID calibration (AC 655, USA). Isooctane (CAS No. 540-84-1) was supplied by Vetec Química Fina Ltda, Brazil (> 99.5\%, UV/HPLC (high-performance liquid chromatography)), and used as an APCI reagent. Methanol (CAS No. 67-56-1), sodium trifluoroacetate (NaTFA, CAS No. 2923-18-4), L-arginine (CAS No. 74-79-3), and formic acid (HCOOH, CAS No. 64-18-6) were also purchased from Sigma-Aldrich Chemicals, USA (> 99\%) and used for the FT-ICR MS calibration. All reagents were used as received without any further purification.

Six PAH standards were supplied by Sigma-Aldrich Chemicals, USA. They were named standards A1-A6 and they are: standard A1, 2,9-dipropylanthra[2,1,9-def:6,5, 10d'e'f']diisoquinoline 1,3,8,10(2H,9H)tetrone ( $\geq 97 \%$, HPLC; CAS No. 59442-38-5); standard A2, EPA 8100 PAH additional components mix (97\%, HPLC; product by Sigma-Aldrich reference number 44694-U); standard A3, benz $[a]$ anthracene (98\%, HPLC; CAS No. 56-55-3); standard A4, coronene ( $\geq 99 \%$, HPLC; CAS No. 191-07-1); standard A5, n,n'-bis(3-pentyl)perylene$3,4,9,10$-bis(dicarboximide) ( $\geq 99 \%$, HPLC; CAS No. 110590-81-3); and standard A6, polynuclear aromatic hydrocarbons (97\%, HPLC; CAS No. 110-82-7).

The SAP compound's fractions were separated by a preparative liquid chromatography column under mediumto-low vacuum for two crude oil samples, supplied by PETROBRAS, Brazil. The physicochemical properties of the two crude oils and the amounts of their respective SAP fractions are detailed in Table 1. For the fractionation, approximately $20 \mathrm{~g}$ of silica (230-400 mesh) was activated at $120^{\circ} \mathrm{C}$ for $12 \mathrm{~h}$ and packed into a glass column of $1.6 \mathrm{~cm}$ diameter. To the top of the column, $200 \mathrm{mg}$ of crude oil was added. Successive elution was performed with $200 \mathrm{~mL}$ of hexane (99\% PA), $200 \mathrm{~mL}$ of dichloromethane:hexane $1: 1(\% \mathrm{v} / \mathrm{v})(99 \%$ PA for dichloromethane) and $200 \mathrm{~mL}$ of methanol $(99.9 \%$, HPLC), in order to separate the 
Table 1. Physicochemical properties of the two crude oils used for saturates, aromatics and polar (SAP) fraction production. The confidence interval ${ }^{a}$ associated with the numerical data is shown in parentheses

\begin{tabular}{lcccccccc}
\hline Crude oil & API gravity & $\begin{array}{c}\text { Total acid } \\
\text { number / } \\
\left(\mathrm{mg} \mathrm{KOH} \mathrm{g}^{-1}\right)\end{array}$ & $\begin{array}{c}\text { Kinematic } \\
\text { viscosity at } \\
40^{\circ} \mathrm{C} / \mathrm{cSt}\end{array}$ & $\begin{array}{c}\text { Pour point / } \\
{ }^{\circ} \mathrm{C}\end{array}$ & $\begin{array}{c}\text { Total sulfur / } \\
\text { wt.\% }\end{array}$ & $\begin{array}{c}\text { Saturates / } \\
\text { wt. \% }\end{array}$ & $\begin{array}{c}\text { Aromatic / } \\
\text { wt.\% }\end{array}$ & $\begin{array}{c}\text { Polar / } \\
\text { wt. \% }\end{array}$ \\
\hline 1 & $27.88(0.15)$ & $0.314(0.024)$ & $20.42(0.25)$ & -12.0 & $0.3714(0.001)$ & 61.7 & 24.4 & 13.9 \\
2 & $34.46(0.55)$ & $0.095(0.009)$ & $31.13(0.23)$ & 6.0 & $0.0575(0.001)$ & 75.5 & 15.0 & 9.6 \\
\hline
\end{tabular}

${ }^{a}$ Confidence interval $(\mathrm{CI})$ values were calculated according to equation $\mathrm{CI}=$ standard deviation $\times\left[4.3 /(3)^{1 / 2}\right]$, where 4.3 means the value of $t($ statistical parameter) for 2 degrees of freedom and 95\% confidence level; ${ }^{b}$ the American Petroleum Institute gravity, or API gravity, is a measure inversely proportional to the relative density of the petroleum.

fractions of saturates, aromatics and polar compounds, respectively. The solvents were removed using a rotary vacuum evaporator to recover the SAP fractions. The results are described in Table 1; the percentages of saturated fractions produced from the two crude oil samples, named as fractions $S_{A}$ and $S_{B}$, were equal to 62 and 76 wt.\%, respectively.

\section{Preparation of paraffins/PAH blends}

To evaluate the efficiency of the APCI(+) technique to ionize HCs selectively, a paraffin sample (standard P4) was doped with coronene (standard A4) at concentrations of $2.5,5,15$ and $25 \mu \mathrm{g} \mathrm{mL}^{-1}$. Previously, the paraffin and coronene solutions were singly prepared at ca. $0.5 \mathrm{mg} \mathrm{mL}^{-1}$ in isooctane.

\section{APCl(+)FT-ICR MS}

FT-ICR MS analysis was performed using a 9.4 T Q-FT-ICR MS hybrid (Solarix, Bruker Daltonics, Bremen, Germany) equipped with a commercial APCI source (Bruker Daltonics, Bremen, Germany) set to operate over $m / z$ 200-2000. The paraffins and PAH commercial standards, saturated fractions, and paraffin/PAH mixtures were analyzed using positive ionization mode, $\operatorname{APCI}(+)$. The samples were diluted in isooctane to $0.5 \mathrm{mg} \mathrm{mL}^{-1}$. The resulting solution was sonicated for $60 \mathrm{~min}$ at $40{ }^{\circ} \mathrm{C}$ and directly infused with a flow rate of $20 \mu \mathrm{L} \mathrm{min}^{-1}$. The APCI(+) source conditions were as follows: nebulizer nitrogen gas temperature and pressure of 2.0 bar and $320^{\circ} \mathrm{C}$, capillary voltage of $4 \mathrm{kV}$, transfer capillary temperature of $180^{\circ} \mathrm{C}$, drying gas flow rate of $4 \mathrm{~L} \mathrm{~min}^{-1}$, end plate offset of $500 \mathrm{~V}$, skimmer of $35 \mathrm{~V}$, collision voltage of $-1.5 \mathrm{~V}$, and corona discharge of $9 \mu \mathrm{A}$.

In the FT-ICR MS analyzer, a $0.02 \mathrm{~s}$ ion accumulation time was used in the hexapole followed by sample transport to the analyzer cell (ICR) through the multipole ion guide system (another hexapole). Each spectrum was acquired using 200 scans of time-domain transient signals in
4 megapoint time-domain data sets. The front and back trapping voltages in the ICR cell were +0.80 and $+0.85 \mathrm{~V}$, respectively, for positive ionization mode. All mass spectra were externally calibrated using L-arginine $(200-2000 \mathrm{~m} / \mathrm{z})$, then internally recalibrated using the most abundant homologous alkylated compounds in each sample. ${ }^{17-22}$ The tandem mass spectrometry $\left(\mathrm{MS}^{2}\right)$ experiments were performed on a quadrupole coupled to an FT-ICR mass spectrometer, Q-FT-ICR MS. APCI(+)MS/MS experiments were performed using collision energies of $15-30 \%$ for the ions of $\mathrm{m} / \mathrm{z} 561,589,603,645,673$, and 701 , and $0-30 \%$ for the two PAH commercial standards (ions of $\mathrm{m} / \mathrm{z} 229$ and 301). ${ }^{23}$

The resolving power $\left(\mathrm{m} / \Delta \mathrm{m}_{50 \%}\right.$ from 420,000 to 530,000 , where $\mathrm{m}$ corresponds to $\mathrm{m} / \mathrm{z} 400$ and $\Delta \mathrm{m}_{50 \%}$ is the full peak width at half-maximum peak height) and mass accuracy lower than 1-3 ppm provided the unambiguous molecular formula assignments for all singly charged molecular ions. The mass spectra were acquired and then processed with a custom algorithm specifically developed for petroleum data using the Composer software package. ${ }^{24}$ The MS data were processed and the elemental compositions of the molecules were determined by measuring the $\mathrm{m} / \mathrm{z}$ values. Class, DBE distributions and $\mathrm{CN}$ versus DBE plots were constructed to allow the interpretation of the results. ${ }^{1,3,4,13,17,25}$ For the $\mathrm{CN}$ versus $\mathrm{DBE}$ and $\mathrm{DBE}$ versus intensity plots, DBE was the number of rings added and the number of double bonds in each molecular structure. The unsaturation level of each compound can be deduced directly from its DBE value, according to equation 1 :

$$
\mathrm{DBE}=\mathrm{C}-\frac{\mathrm{H}}{2}+\frac{\mathrm{N}}{2}+1
$$

where $\mathrm{C}, \mathrm{H}$ and $\mathrm{N}$ are the numbers of carbon, hydrogen and nitrogen atoms, respectively, in the molecular formula.

\section{High-temperature gas chromatography (HTGC)}

The HTGC analyses of paraffin standards and saturate fractions were performed using Agilent 6890 N Network 
GC System customized by Analytical Control (AC, Netherlands) with a flame ionization detector (FID). Paraffin samples were diluted in $\mathrm{CS}_{2}$ at $2 \mathrm{wt} . \%$, and $1 \mu \mathrm{L}$ of sample was injected into the HT750 capillary column $(5 \mathrm{~m} \times 0.53 \mathrm{~mm} \times 0.1 \mu \mathrm{m}$, from AC) using an auto-injector. The HTGC was calibrated using a standard mixture containing carbon numbers from $\mathrm{C}_{5}$ to $\mathrm{C}_{120}$, according to the ASTM D7169-0 $05^{26}$ standard. The analyses were performed under a helium flow rate of $15 \mathrm{~mL} \mathrm{~min}^{-1}$ and a temperature program of -20 to $430{ }^{\circ} \mathrm{C}$ at $10{ }^{\circ} \mathrm{C} \mathrm{min}^{-1}$.

The initial temperature of the injection port was $50^{\circ} \mathrm{C}$, which was increased to $430{ }^{\circ} \mathrm{C}$ at a rate of $15{ }^{\circ} \mathrm{C} \mathrm{min}-1$, and then kept constant for $26 \mathrm{~min}$. The detector was kept at $430{ }^{\circ} \mathrm{C}$. The data acquisition frequency was $10 \mathrm{~Hz}$. The HTGC data were analyzed using GC ChemStation Rev. B.03.01-1.1 SR-[317] software, and version 8.4.0.0.

\section{${ }^{1} \mathrm{H}$ and ${ }^{13} \mathrm{C}$ NMR spectroscopy}

${ }^{1} \mathrm{H}$ and ${ }^{13} \mathrm{C}$ NMR spectra of the five paraffin standards were recorded on a Varian VNMRS 400 spectrometer, operating at $9.4 \mathrm{~T}$ and using a $5 \mathrm{~mm}$ broadband ${ }^{1} \mathrm{H} / \mathrm{X} / \mathrm{D}$ probe. The experiments were performed at $25{ }^{\circ} \mathrm{C}$, using $20 \mathrm{mg}$ of paraffin diluted in $0.6 \mathrm{~mL}$ of deuterated chloroform. Tetramethylsilane (TMS) was used as an internal standard for setting the chemical shift scale. A spectral width of $6410.3 \mathrm{~Hz}$ was used, with a relaxation delay of $1.5 \mathrm{~s}$, and 512 transients were accumulated for each spectrum. The relaxation agent $\operatorname{Cr}(\mathrm{Acac})_{3}$ diluted in deuterated chloroform at $50 \mathrm{mM}$ was also employed. For the ${ }^{13} \mathrm{C}$ NMR, the same solution used in the ${ }^{1} \mathrm{H}$ NMR experiments was employed, with a spectral width of $25510.2 \mathrm{~Hz}$, a relaxation delay of $15 \mathrm{~s}$ and 20,000 scans, with a pulse flip angle of $90^{\circ}(9.5 \mathrm{~ms})$. The decoupler mode was switched off during the pulse and the standby time was switched on during data acquisition to avoid nuclear Overhauser Increase Effect (NOE). The spectra obtained for the paraffin standards were integrated from 9.0 to $6.0 \mathrm{ppm}$ (for the aromatic hydrogen region) and from 4.0 to $0.0 \mathrm{ppm}$ (for the aliphatic hydrogen region). This procedure was analogous to the method described by Oliveira et al..$^{27}$

\section{Two-dimensional gas chromatography (GC×GC-MS)}

The paraffin standards (P1-P3) and two saturated fractions from petroleum (denominated by fractions $S_{A}$ and $\mathrm{S}_{\mathrm{B}}$ ) (all at $500 \mathrm{mg} \mathrm{L}^{-1}$ ) were analyzed by $\mathrm{GC} \times \mathrm{GC}-\mathrm{MS}$ (Shimadzu QP2010 Ultra system, USA) with a ZX1GC $\times$ GC modulator (Zoex, Houston, TX, USA). The chromatographic separation was performed by two columns, in which the first column was based on DB-5, 5\% phenyl and $95 \%$ methylpolysiloxane $(30 \mathrm{~m} \times 0.25 \mathrm{~mm}$ i.d. $\times 0.25 \mu \mathrm{m}$ film thickness, J\&W Scientific, Agilent Technologies, USA) and the second column was DB-17, 50\% phenyl and $50 \%$ methyl-polysiloxane $(1.8 \mathrm{~m} \times 0.10 \mathrm{~mm} \times 0.10 \mu \mathrm{m}$, J\&W Scientific, Agilent Technologies, USA). The oven temperature programming started at $140{ }^{\circ} \mathrm{C}$ for $5 \mathrm{~min}$, then a ramp of $2{ }^{\circ} \mathrm{C} \min ^{-1}$ to $310^{\circ} \mathrm{C}$, and finally $310{ }^{\circ} \mathrm{C}$ for $10 \mathrm{~min}$, for a total analysis time of $100 \mathrm{~min}$. The injector temperature/interface and ion source were maintained at $300{ }^{\circ} \mathrm{C}$. The analyses were performed using the splitless mode, and helium gas (5.0) was used as a constant carrier gas at a flow of $1.5 \mathrm{~mL} \mathrm{~min}^{-1}$. The mass range was examined from 50 to $600 \mathrm{Da}$, with a modulation period of $8 \mathrm{~s}$. GC Image software (ZOEX Corporation, Houston, Texas, USA) was used for the identification of compounds.

\section{Results and Discussion}

\section{Paraffin standards}

Figures 1a-1e show the APCI(+)FT-ICR mass spectra obtained for the five paraffin standards (standards P1-P5). Standards P1, P2 and P3 had an $\mathrm{m} / \mathrm{z}$ distribution ranging from 200 to 650, with average molecular weights $\left(\mathrm{M}_{\mathrm{w}} \mathrm{s}\right)$ centered at $\mathrm{m} / \mathrm{z}, 431,444$ and 572, respectively. These distributions corresponded to carbon numbers $(\mathrm{CNs})$ ranging from $\mathrm{C}_{16}$ to $\mathrm{C}_{48}$. On the other hand, wider distributions of HCs $(m / z, 200-800$ and $m / z, 200-1200)$ were observed for standards P4 and P5, being indicative of the existence of high molecular weight $\mathrm{HCs}$ with $\mathrm{CNs}$ ranging from $\mathrm{C}_{16}$ to $\mathrm{C}_{58}$ and $\mathrm{C}_{30}$ to $\mathrm{C}_{76}$, respectively. These species were ionized via loss of a hydride $\left(\mathrm{H}^{-}\right)$, thus forming $[\mathrm{M}-\mathrm{H}]^{+}$cations.

The inset around the $m / z, 323$ region in Figure 1 displays a major signal of $\mathrm{m} / \mathrm{z} 323.3673$ corresponding to the $\left[\mathrm{C}_{23} \mathrm{H}_{48}-\mathrm{H}\right]^{+}$cation with $\mathrm{DBE}=0$. Low abundance heteroatom $\mathrm{HC}$ species corresponding to nitrogenated and oxygenated compounds were also detected as $\left[\mathrm{C}_{22} \mathrm{H}_{44} \mathrm{O}-\mathrm{H}\right]^{+}$and $\left[\mathrm{C}_{19} \mathrm{H}_{36} \mathrm{~N}_{2} \mathrm{O}_{2}-\mathrm{H}\right]^{+}$cations, with $\mathrm{m} / \mathrm{z}, 323.3309$ and 323.2693 and DBEs of 1 and 2, respectively. These compounds originated from ion molecule reactions between sheath gas $\left(\mathrm{N}_{2}\right)$, APCI reagent (isooctane) and $\mathrm{O}_{2}$ (from ambient atmosphere) with $\mathrm{HC}$ compounds in the presence of the corona discharge..$^{7,16}$

Generally, $\mathrm{APCI}(+)$ analysis demonstrated to be efficient in the ionizing of $\mathrm{HCs}$. Therefore, $\mathrm{APCI}(+)$ is a desirable technique, since the identification of saturated and/or unsaturated HCs (specifically $n$-paraffins, isoparaffins and cycloparaffins) are the major contributors to understanding the process of paraffin deposition that occurs during the production, transportation and oil refining. ${ }^{16}$ 


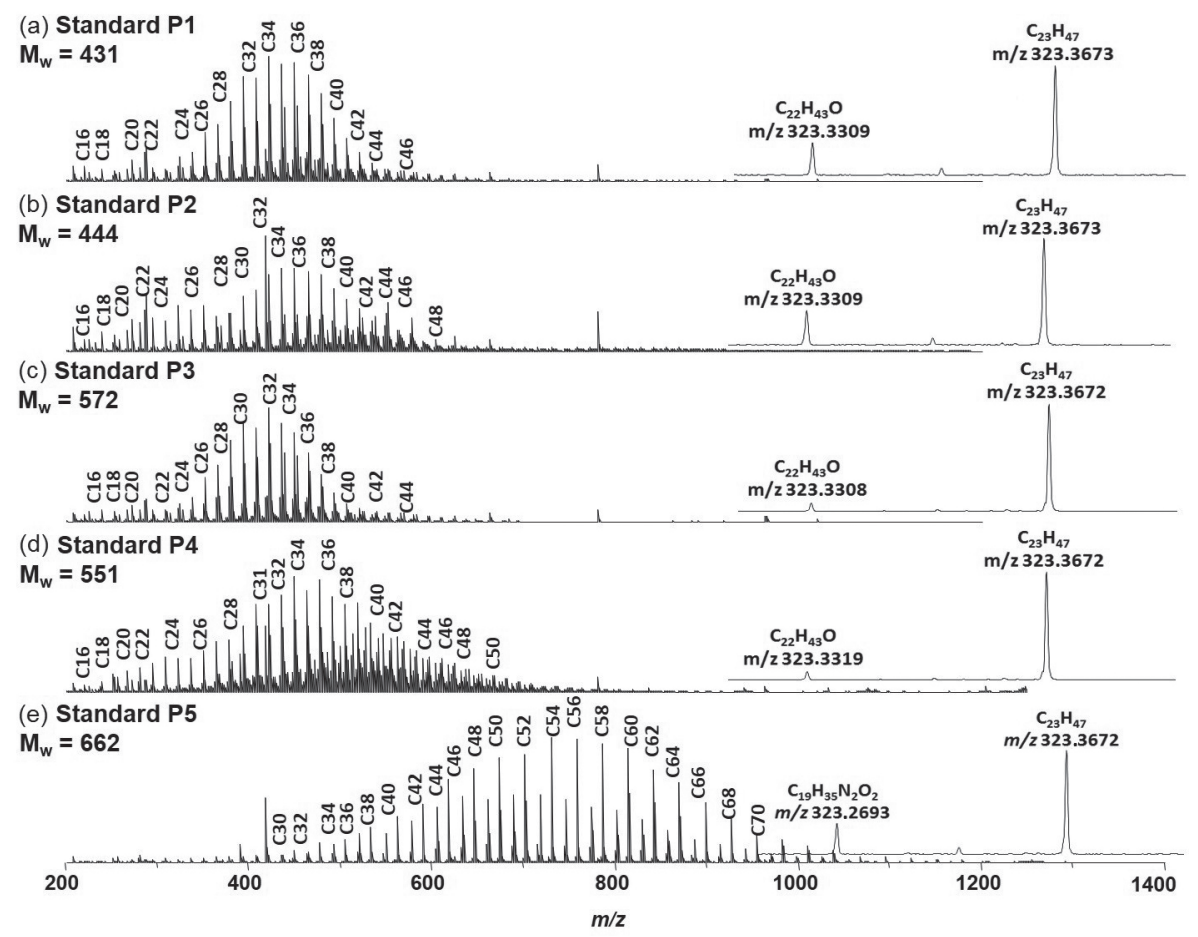

Figure 1. APCI(+)FT-ICR mass spectra for paraffins standard P1-P5 prepared at $0.5 \mathrm{mg} \mathrm{mL}^{-1}$ in isooctane.

Chromatograms from the HTGC analysis of standards P1-P5 are shown in Figures S1a-S1e (Supplementary Information (SI) section), and were done in order to establish a comparison with the APCI(+)FT-ICR MS technique. HCs were identified on the basis of retention times of known $n$-paraffins, where their $\mathrm{CNs}$ ranged from $\mathrm{C}_{10}$ to $\mathrm{C}_{100}$. Figure $\mathrm{S} 1$ (SI section) shows that the CNs of $n$-paraffins present in standards P1-P3 varied from $\mathrm{C}_{15}$ to $\mathrm{C}_{39}$, whereas for standards $\mathrm{P} 4$ and $\mathrm{P} 5$ varied from $\mathrm{C}_{18}-\mathrm{C}_{46}$ and $\mathrm{C}_{8}-\mathrm{C}_{100}$, respectively. However, the HTGC technique identifies only saturated $\mathrm{HCs}$, whereas branched and cyclic HCs are not resolved. ${ }^{6,7}$ On the other hand, $\mathrm{APCI}(+)$ FT-ICR MS is able to distinguish the chemical composition of paraffins between saturate/branch and cyclic HCs. ${ }^{16}$

In order to facilitate the visualization of APCI(+)FT-ICR MS data, diagrams of classes were constructed, and their abundances were in the following order: $\mathrm{HC}[\mathrm{H}]>\mathrm{N}[\mathrm{H}]>\mathrm{O}[\mathrm{H}]>\mathrm{NO}[\mathrm{H}]$ ca. $\mathrm{NO}_{2}[\mathrm{H}]>$ $\mathrm{O}_{2}[\mathrm{H}]>$ other (the transfer of protons or abstraction of hydrides is represented by $[\mathrm{H}]$ associated with the class who it refers) (Figure 2a). APCI(+) assisted by isooctane reagent proved to be effective for the selective ionization of HCs, where these species were dominant in standards P3 and P4 (Figure 2a). All paraffins standards showed heteroatomic compounds, where a higher abundance of these compound classes was found in standards P1 and P5 (Figure 2a).

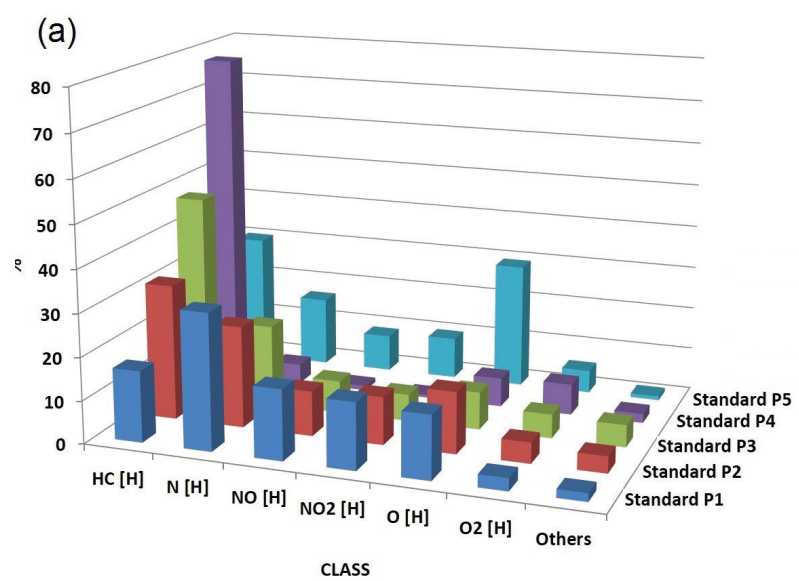

(b)

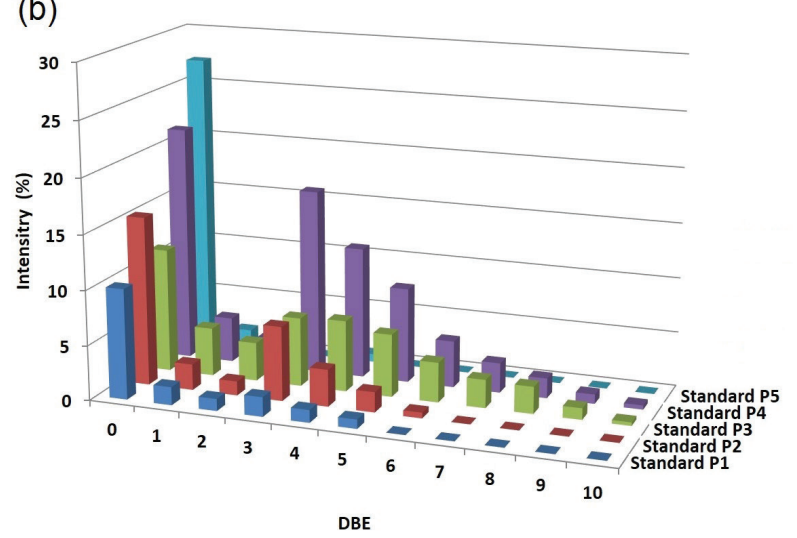

Figure 2. Class diagrams (a) and DBE distribution for HC class (b) for paraffins standard P1-P5 obtained from APCI(+)FT-ICR MS data. 
Plots of DBE versus intensity were also constructed (Figure 2b), and a lower DBE distribution was observed for standards P1, P2 and P5, whereas for standards P3 and $\mathrm{P} 4$, the DBE values varied from 0 to 9 . DBE values higher than 1 are indicative of the presence of polycyclic paraffins (cycloalkanes and naphthenes) as well as of PAH species. Despite the existence of $\mathrm{HCs}$ with $\mathrm{DBE} \neq 0$, the relative abundance of saturate HCs (i.e., DBE $=0$ ) were always highest (Figure 2b).

The chemical profile of $\mathrm{CN}$ distribution among the paraffin samples is shown in Figures S2a-S2e (SI section) from the construction of $\mathrm{DBE} \times \mathrm{CN}$ plots. Differently from other samples, a wider and richer $\mathrm{CN}$ distribution was only observed for standard P5, which had aliphatic $\mathrm{HCs}\left(\mathrm{DBE}=0\right.$ ) containing $\mathrm{CNs}$ ranging from $\mathrm{C}_{20}$ to $\mathrm{C}_{78}$, with the maximum distribution centered at $\mathrm{C}_{47}$. This result was in good agreement with HTGC data, which showed a $\mathrm{CN}$ distribution ranging from $\mathrm{C}_{8}$ to $\mathrm{C}_{86}$ with a maximum centered at $\mathrm{C}_{46}$ (Figure $\mathrm{S} 1 \mathrm{e}$, SI section). For standards $\mathrm{P} 3$ and $\mathrm{P} 4$, the detection of polycyclic HCs was more evident (Figures S2c-S2d, SI section), where two sets of distributions are visualized: aliphatic $\mathrm{HCs}(\mathrm{DBE}=0$ with CNs of $\mathrm{C}_{15}-\mathrm{C}_{60}$ ) and cyclic and polycyclic HCs (DBE $\geq 2$ and $\mathrm{DBE} \leq 7$ containing $\mathrm{CNs}$ of $\mathrm{C}_{20}-\mathrm{C}_{58}$ ). HTGC data confirmed the existence of $n$-paraffins containing $\mathrm{CNs}$ in the ranges of $\mathrm{C}_{20}-\mathrm{C}_{39}$ and $\mathrm{C}_{20}-\mathrm{C}_{46}$ for standards $\mathrm{P} 3$ and $\mathrm{P} 4$, respectively (Figures S1c-S1d, SI section). Low intensity and unresolved peaks due to unidentified compounds were observed in HTGC chromatograms obtained for standards P1-P4, as well as a shift of baseline (Figures S1a-S1d, SI section). This behavior is indicative of the existence of polycyclic HCs, which were confirmed by the results obtained by $\mathrm{APCI}(+)$ technique.

To confirm the structure and connectivity of saturated and cyclic HCs in the paraffin standards, and also to discard the existence of PAHs for the set of molecules of $\mathrm{HC}[\mathrm{H}]$ class with $\mathrm{DBE} \geq 4$, collision induced dissociation (CID) experiments were performed for HCs ions having different DBEs (from 0 to 8 ) in standard P4. Figures 3a-3f show the APCI(+)MS/MS results for the ions of $\mathrm{m} / \mathrm{z}$ $701.7896\left(\left[\mathrm{C}_{50} \mathrm{H}_{102}-\mathrm{H}\right]^{+}\right.$, error $=0.28 \mathrm{ppm}$ and $\mathrm{DBE}=0$, Figure 3a), $m / z 645.72343\left(\left[\mathrm{C}_{46} \mathrm{H}_{94}-\mathrm{H}\right]^{+}\right.$, error $=5.81 \mathrm{ppm}$ and $\mathrm{DBE}=0$, Figure $3 \mathrm{~b}), m / z 561.5378\left(\left[\mathrm{C}_{41} \mathrm{H}_{70}-\mathrm{H}\right]^{+}\right.$, error $=2.85 \mathrm{ppm}$ and $\mathrm{DBE}=2$, Figure $3 \mathrm{c}), \mathrm{m} / z 673.6625$ $\left(\left[\mathrm{C}_{49} \mathrm{H}_{86}-\mathrm{H}\right]^{+}\right.$, error $=3.12 \mathrm{ppm}$ and $\mathrm{DBE}=3$, Figure $\left.3 \mathrm{~d}\right)$, $m / z 589.5706\left(\left[\mathrm{C}_{43} \mathrm{H}_{74}-\mathrm{H}\right]^{+}\right.$, error $=0.01 \mathrm{ppm}$ and $\mathrm{DBE}=8$, Figure 3e $)$ and $m / z 603.5803\left(\left[\mathrm{C}_{44} \mathrm{H}_{76}-\mathrm{H}\right]^{+}\right.$, error $=3.63 \mathrm{ppm}$ and $\mathrm{DBE}=8$, Figure $3 \mathrm{f}$ ). All ions showed similar fragmentation profiles with subsequent losses of $28 \mathrm{Da}$, referring to the ethene group $\left(\mathrm{CH}_{2}=\mathrm{CH}_{2}\right)$. This result is similar to that obtained by $\mathrm{Wu}$ et al. ${ }^{28}$ who analyzed vacuum gas oil saturates by DESI-Orbitrap. Generally, this behavior provides evidence that PAHs are not a significant portion of the paraffins standards. ${ }^{22,23}$

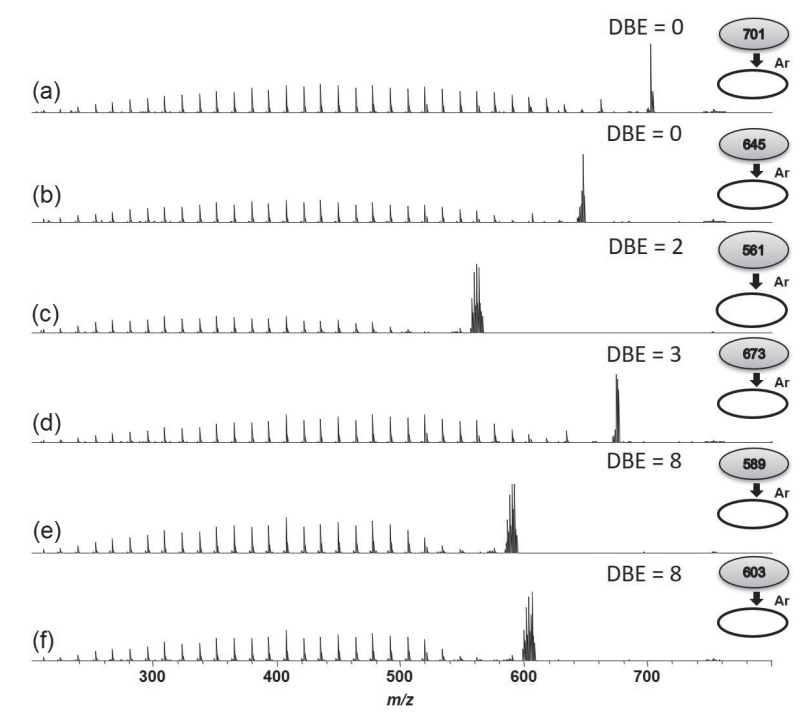

Figure 3. APCI(+)-MS/MS for ions at (a) $m / z 701(\mathrm{DBE}=0)$, (b) $\mathrm{m} / z 645$ (DBE = 0), (c) $m / z 561(\mathrm{DBE}=2),(\mathrm{d}) \mathrm{m} / z 673(\mathrm{DBE}=3),(\mathrm{e}) \mathrm{m} / z, 589$ $(\mathrm{DBE}=8)$ and (f) $m / z 603(\mathrm{DBE}=8)$, corresponding to standard P4.

From the APCI(+)MS/MS spectra, DBE versus $\mathrm{CN}$ plots were constructed for ions of $m / z, 701,645,561,673$, 589, and 603 (standard P4, Figures 4a-4f), corresponding to the $\mathrm{HC}[\mathrm{H}]$ class. For the ions of $\mathrm{DBE}=0(\mathrm{~m} / \mathrm{z}, 701$ and 645), the produced fragments showed a continuous distribution of $\mathrm{CNs}$ ranging from $\mathrm{C}_{18}$ to $\mathrm{C}_{43}$ with $\mathrm{DBE}=0$ for $n$-paraffin molecules (Figures $4 \mathrm{a}-4 \mathrm{~b}$ ). However, for cyclic paraffins $(\mathrm{DBE}=8$, Figures $4 \mathrm{e}-4 \mathrm{f}$ ), abundant and minority groups of fragments were observed at $\mathrm{DBE}=2$ and 5-8 (cyclic HCs fragments) as well as the production of a non-continuous distribution of fragments at $\mathrm{DBE}=0$ containing $\mathrm{CNs}$ between $\mathrm{C}_{16}$ and $\mathrm{C}_{40}$. Hence, it is possible to note that the fragmentation profiles of saturate and cyclic HCs are similar to one another, but completely different from PAH molecules. ${ }^{28}$

With the aims of quantitatively evaluating the possible presence of PAHs in the paraffin standards and better understanding their structural features, ${ }^{1} \mathrm{H}$ and ${ }^{13} \mathrm{C}$ NMR spectra were recorded, as shown in Figures S3 and S4 (SI section). Due to the higher chemical shift range involved, ${ }^{13} \mathrm{C}$ NMR spectra usually allow a more detailed structural study of paraffins, despite the inferior sensitivity of the ${ }^{13} \mathrm{C}$ NMR technique as compared to ${ }^{1} \mathrm{H}$ NMR. ${ }^{29-32}$

Figure S3 (SI section) shows the ${ }^{1} \mathrm{H}$ NMR spectra of paraffin standard samples, where, essentially, the chemical shifts were assigned to ${ }^{1} \mathrm{H}$ nuclei in methylene groups $\left(\mathrm{CH}_{2}\right)$, labelled as $\mathrm{H}_{\beta}(1.0-1.8 \mathrm{ppm})$, or in methyl groups $\left(\mathrm{CH}_{3}\right)$, labelled as $\mathrm{H}_{\alpha}(0.4-1.0 \mathrm{ppm})$. It is evident that, in all 

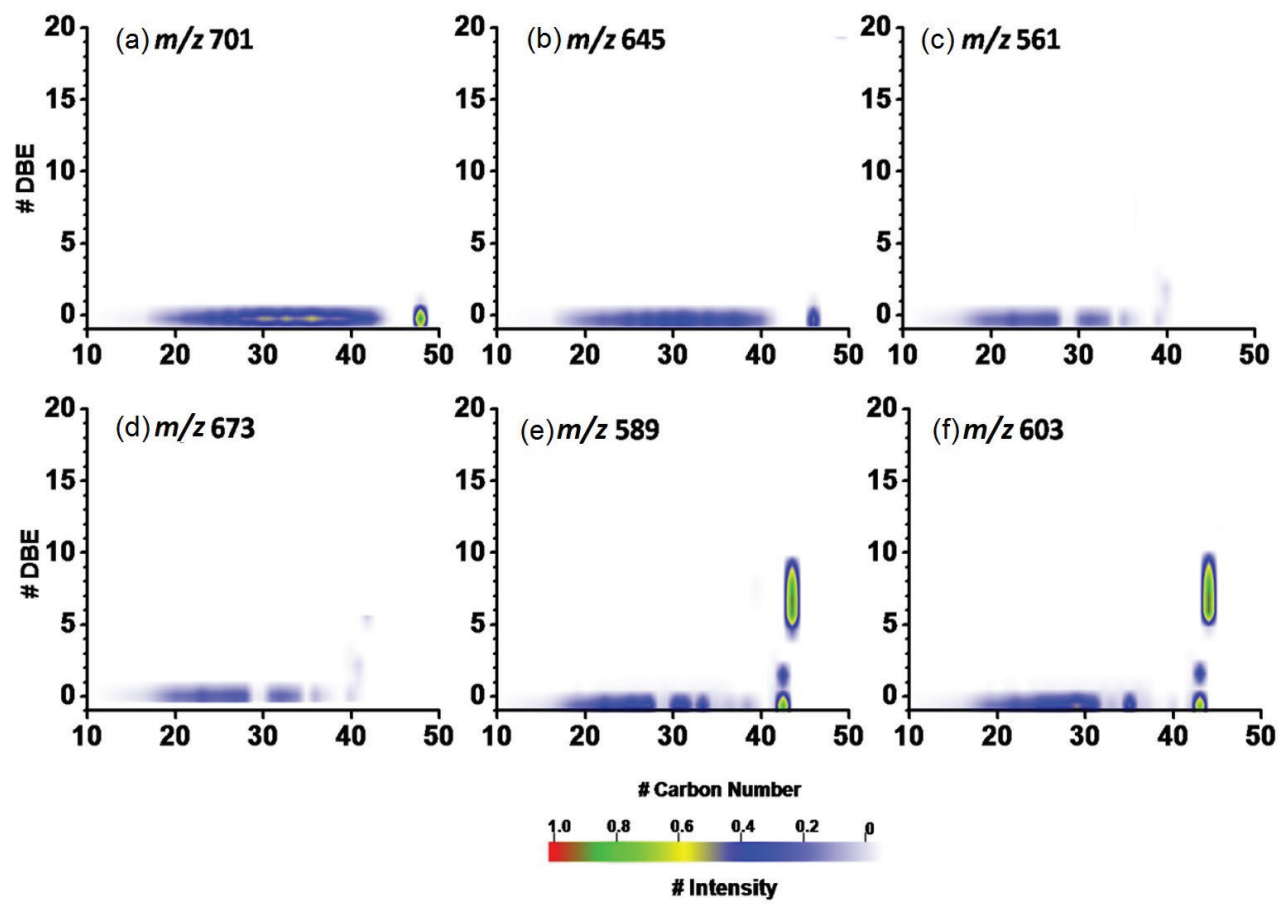

Figure 4. DBE versus $\mathrm{CN}$ plots for the $\mathrm{HC}[\mathrm{H}]$ class from APCI(+)MS/MS data of ions of $m / z, 701$ (a), 645 (b), 561 (c), 673 (d), 589 (e) and 603 (f).

samples, the $\mathrm{H}_{\beta}$ signal (with relative intensity of ca. 90\%) was much more intense than the $\mathrm{H}_{\alpha}$ signal (relative intensity of ca. 10\%) (Table 2). This behavior is typical of $n$ - and isoparaffins with long chains, ${ }^{29-31}$ since methyl groups $\left(\mathrm{H}_{\alpha}\right)$ are present at the paraffin chain end or at the branching points, while methylene groups $\left(\mathrm{H}_{\beta}\right)$ compose the inner structure of the chains in $n$-paraffins and cyclic paraffins. Alcazar-Vara et al. ${ }^{33}$ used ${ }^{1} \mathrm{H}$ and ${ }^{13} \mathrm{C}$ NMR to describe the mechanisms involved in the asphaltene-paraffin interaction and its effect on paraffin precipitation, and it was possible to determine the index of alkyl substitution in aromatic cores as well as the average length of the alkyl chains. ${ }^{33}$

Analyzing the $\mathrm{H}_{\mathrm{ar}}$ (total aromatic hydrogens) content, which was obtained by calculating the relative spectral intensity in the region of the ${ }^{1} \mathrm{H}$ NMR spectra that corresponded to aromatic hydrogens $(\delta 6.5-9.5 \mathrm{ppm})$, it was possible to disregard the presence of PAHs in the paraffin standard samples. Note that $\mathrm{H}_{\mathrm{ar}}$ contents were
$0.0 \mathrm{~mol} \%$, whereas $\mathrm{H}_{\text {alk }}$ (total aliphatic hydrogens) contents were $100.0 \pm 0.0 \mathrm{~mol} \%$ in almost all cases. Also, a good agreement was observed between the APCI(+)-MS and ${ }^{1} \mathrm{H}$ NMR data, with the $\mathrm{H}_{\beta}$ contents being directly associated with the average $M_{w}$ values, which increased in the following order: standard P1 $\left(\mathrm{M}_{\mathrm{w}}=431 \mathrm{Da}\right)<$ standard P2 $\left(\mathrm{M}_{\mathrm{w}}=444 \mathrm{Da}\right)<\operatorname{standard} \mathrm{P} 4\left(\mathrm{M}_{\mathrm{w}}=551 \mathrm{Da}\right)<\operatorname{standard} \mathrm{P} 3$ $\left(M_{w}=571 \mathrm{Da}\right)<\operatorname{standard}$ P5 $\left(\mathrm{M}_{\mathrm{w}}=662 \mathrm{Da}\right)$. It is clear from the data given in Table 2 that the $\mathrm{H}_{\beta}$ contents of the different samples grew exactly in the same order. However, when analyzing the standard deviation of the samples, standards $\mathrm{P} 2, \mathrm{P} 3$, and $\mathrm{P} 4$ presented close values of $\mathrm{H}_{\beta}$. In fact, the $\mathrm{H}_{\beta} / \mathrm{H}_{\alpha}$ ratio in ${ }^{1} \mathrm{H}$ NMR spectra has also shown to be a good indicator of the average chain length of $n$-paraffins. ${ }^{30-32} \mathrm{High}$ deviation observed for the $\mathrm{H}_{\alpha}$ and $\mathrm{H}_{\beta}$ values in standard $\mathrm{P} 5$ can be explained due to replicates analysis performed on different days. Besides, this sample displays a lower solubility in organic solvents at environmental temperature

Table 2. Classification of hydrogen types present in the paraffin standards according to ${ }^{1} \mathrm{H}$ NMR data. The confidence interval associated with the numerical data is shown in parentheses. The analyses were performed in triplicates

\begin{tabular}{|c|c|c|c|c|c|}
\hline \multirow{2}{*}{ Molecular parameter } & \multicolumn{5}{|c|}{ Relative quantity / mol\% } \\
\hline & Standard P1 & Standard P2 & Standard P3 & Standard P4 & Standard P5 \\
\hline $\mathrm{H}_{\mathrm{alk}}^{\mathrm{a}}$ & $100.0(0.0)$ & $100.0(0.0)$ & $100.0(0.0)$ & $100.0(0.0)$ & $100.0(0.1)$ \\
\hline $\mathrm{H}_{\mathrm{ar}}^{\mathrm{b}}$ & $0.0(0.0)$ & $0.0(0.0)$ & $0.0(0.0)$ & $0.0(0.0)$ & $0.0(0.1)$ \\
\hline $\mathrm{H}_{\alpha}{ }^{\mathrm{c}}$ & $11.4(2.9)$ & $10.8(2.9)$ & $9.9(0.8)$ & $10.2(1.2)$ & $5.2(11.1)$ \\
\hline $\mathrm{H}_{\beta}^{\mathrm{d}}$ & $88.6(2.9)$ & $89.2(2.8)$ & $90.1(0.8)$ & $89.8(1.2)$ & $94.8(11.0)$ \\
\hline
\end{tabular}

${ }^{\mathrm{a}}$ Total aliphatic hydrogens; ${ }^{\mathrm{b}}$ total aromatic hydrogens; ${ }^{\mathrm{c}}$ methyl hydrogen atoms; ${ }^{\mathrm{d}}$ methylene hydrogen atoms. 
due to its high $\mathrm{M}_{\mathrm{w}}$ value, thus interfering, in precision of instrument.

Figure S4 (SI section) shows the ${ }^{13} \mathrm{C}$ NMR spectra obtained for the paraffin standards. Similar to what was reported by Cookson and Smith, ${ }^{30}$ and assuming a paraffin molecule modelled as a linear chain, five chemical shifts $(\delta 14.3,23.0,32.2,29.7$, and $30.0 \mathrm{ppm})$ were assigned to chains of the type $\left(\alpha \mathrm{CH}_{3}\right)_{2}\left(\beta \mathrm{CH}_{2}\right)_{2}\left(\gamma \mathrm{CH}_{2}\right)_{2}\left(\delta \mathrm{CH}_{2}\right)_{2}\left(\varepsilon \mathrm{CH}_{2}\right)$, with the mentioned $\delta$ values corresponding to $\alpha \mathrm{CH}_{3}$, $\beta \mathrm{CH}_{2}, \gamma \mathrm{CH}_{2}, \delta \mathrm{CH}_{2}$, and $\varepsilon \mathrm{CH}_{2}$ groups, respectively, whose intensities are given in Table 3. Also, the $\left(\mathrm{BCH}_{2}\right)$, $\left(\gamma \mathrm{CH}_{2}\right)$ and $\left(\delta \mathrm{CH}_{2}\right)$ groups can indicate the presence of cycloparaffinic structures. ${ }^{30,32,34,35}$ Similar to the previously discussed ${ }^{1} \mathrm{H}$ NMR results, the relative intensity due to $\mathrm{\varepsilon CH}_{2}$ groups $(\delta 30.0 \mathrm{ppm})$ is directly related to the average chain length ${ }^{30,32}$ and, thus, to the $\mathrm{M}_{\mathrm{w}}$ values, which increased in the following order: standard $\mathrm{P} 1<$ standard $\mathrm{P} 2<$ standard $\mathrm{P} 4<$ standard $\mathrm{P} 3<$ standard $\mathrm{P} 5$. This behavior is similar to the observed $\mathrm{H}_{\beta}$ contents. On the other hand, the abundance of cycloparaffinic structures (visualized from DBE versus $\mathrm{CN}$ plots, Figure S2, SI section) was correlated with the decrease of $\alpha \mathrm{CH}_{3}, \gamma \mathrm{CH}_{2}$ and $\delta \mathrm{CH}_{2}$ contents. Therefore, the cyclization degree decreased in the following order: standard $\mathrm{P} 1<$ standard $\mathrm{P} 2<$ standard $\mathrm{P} 3 \approx$ standard $\mathrm{P} 4<$ standard P5 (Table 3). As observed in the content of $\mathrm{H}_{\beta}$, standards $\mathrm{P} 3$ and $\mathrm{P} 4$ presented close values of relative quantity (mol\%), while standard P5 presented a value approximately $10 \%$ higher.

GC $\times$ GC-MS elucidated the molecular composition of HCs, classifying them as linear, branched, cyclic and PAHs. Herein, three paraffin standard samples were investigated (standards P1-P3), and the two-dimensional chromatograms results are shown in Figures 5a-5c. A similar chemical profile containing $\mathrm{CNs}$ of linear-HCs ranging from $\mathrm{C}_{19}$ to $\mathrm{C}_{36}$ was identified for all samples. Other $\mathrm{HC}$ groups were also detected, such as alkyl-cyclopentane (A), alkyl-cyclohexene (B), alkyl-methyl-cyclohexene (C) and branched HCs (D), which were mostly present in standards P2 and P3 (Figures 5b-5c).
Despite the similarity in chemical composition among the three standards, paraffin standard P1 had a greater abundance of linear and branched HCs, while the other two samples had a greater abundance of cyclic paraffins, with DBEs of 1 (alkyl-cyclopentane) and 2 (alkyl-cyclohexene and alkyl-methyl-cyclohexene). Deursen et al. ${ }^{35}$ also employed a two-dimensional system coupled to TOF-MS for analysis of crude oil samples, where it was possible to distinguish between saturated and cyclic HCs compounds. $\mathrm{GC} \times \mathrm{GC} / \mathrm{q}-\mathrm{MS}$ results were in partial agreement with the $\mathrm{DBE}$ versus $\mathrm{CN}$ plots, as shown for the $\mathrm{HC}[\mathrm{H}]$ class from APCI(+)FT-ICR MS data (Figure S2, SI section). Cyclic paraffins were mostly present, although containing a higher amplitude of DBE values (DBE from 1 to 7) with the maximum distribution centered at $\mathrm{DBE}=3$ and $\mathrm{CN}$ of $\mathrm{C}_{30}$ (for standard P2) and $\mathrm{C}_{36}$ (for standard P3, see Figures S2b-S2c, SI section). This difference is due to the fact that $\mathrm{APCI}(+)$ renders the ionization of a wider distribution of $\mathrm{HCs}$ when compared with the $\mathrm{GC} \times \mathrm{GC} / \mathrm{q}-\mathrm{MS}$ technique. Finally, the presence of PAHs was also not detected in any of three samples in the $\mathrm{GC} \times \mathrm{GC} / \mathrm{q}-\mathrm{MS}$ data, being similar to NMR and APCI(+)FT-ICR MS results. ${ }^{35-38}$

\section{$\mathrm{PAH}$ standards and $\mathrm{PAH} /$ paraffin blends}

The ability of APCI(+) to ionize PAH standards was also evaluated. Six commercial standards were investigated, and their APCI(+)FT-ICR mass spectra are displayed in Figures S5a-S5f (SI section). In general, the PAHs were ionized via proton transfer $\left([\mathrm{M}+\mathrm{H}]^{+}\right)$, and the values of theoretical mass, experimental mass, mass error (ppm), molecular formula and DBE are shown in Table 4. APCI(+) caused the ionization of a single molecule for the standards $\mathrm{A} 1, \mathrm{~A} 3, \mathrm{~A} 4$ and $\mathrm{A} 5$, corresponding to $\left[\mathrm{C}_{30} \mathrm{H}_{22} \mathrm{~N}_{2} \mathrm{O}_{4}+\mathrm{H}\right]^{+}$, $\left[\mathrm{C}_{18} \mathrm{H}_{12}+\mathrm{H}\right]^{+},\left[\mathrm{C}_{24} \mathrm{H}_{12}+\mathrm{H}\right]^{+}$and $\left[\mathrm{C}_{34} \mathrm{H}_{30} \mathrm{~N}_{2} \mathrm{O}_{4}+\mathrm{H}\right]^{+}$species, respectively. For standard A1, signals with $m / z<300$ corresponded to fragmentation products (Figure S5a, SI section). In all cases, an accurate mass lower than $3 \mathrm{ppm}$ was reported as well as DBE values between 9 and 21. For

Table 3. Classification of carbon types present in the paraffin standards according to ${ }^{13} \mathrm{C}$ NMR data. The confidence interval associated with the numerical data is shown in parentheses. The analyses were performed in triplicates

\begin{tabular}{lccccc}
\hline \multirow{2}{*}{ Molecular parameter } & \multicolumn{5}{c}{ Relative quantity / mol\% } \\
\cline { 2 - 6 } & Standard P1 & Standard P2 & Standard P3 & Standard P4 & Standard P5 \\
\hline$\alpha \mathrm{CH}_{3}$ & $7.4(1.0)$ & $6.6(2.5)$ & $6.2(2.5)$ & $5.8(1.8)$ & $4.1(0.9)$ \\
$\mathrm{CCH}_{2}$ & $7.8(0.6)$ & $6.9(2.2)$ & $6.6(2.6)$ & $6.2(2.1)$ & $3.1(1.1)$ \\
$\gamma \mathrm{CH}_{2}$ & $7.7(0.3)$ & $6.8(1.6)$ & $6.4(1.6)$ & $5.8(0.7)$ & $2.8(0.8)$ \\
$\delta \mathrm{CH}_{2}$ & $7.9(1.2)$ & $7.0(0.5)$ & $6.6(0.1)$ & $6.3(0.7)$ & $2.4(4.3)$ \\
$\varepsilon \mathrm{CH}_{2}$ & $69.2(0.7)$ & $72.7(6.8)$ & $74.2(6.8)$ & $75.9(5.2)$ & $87.3(6.1)$ \\
\hline
\end{tabular}



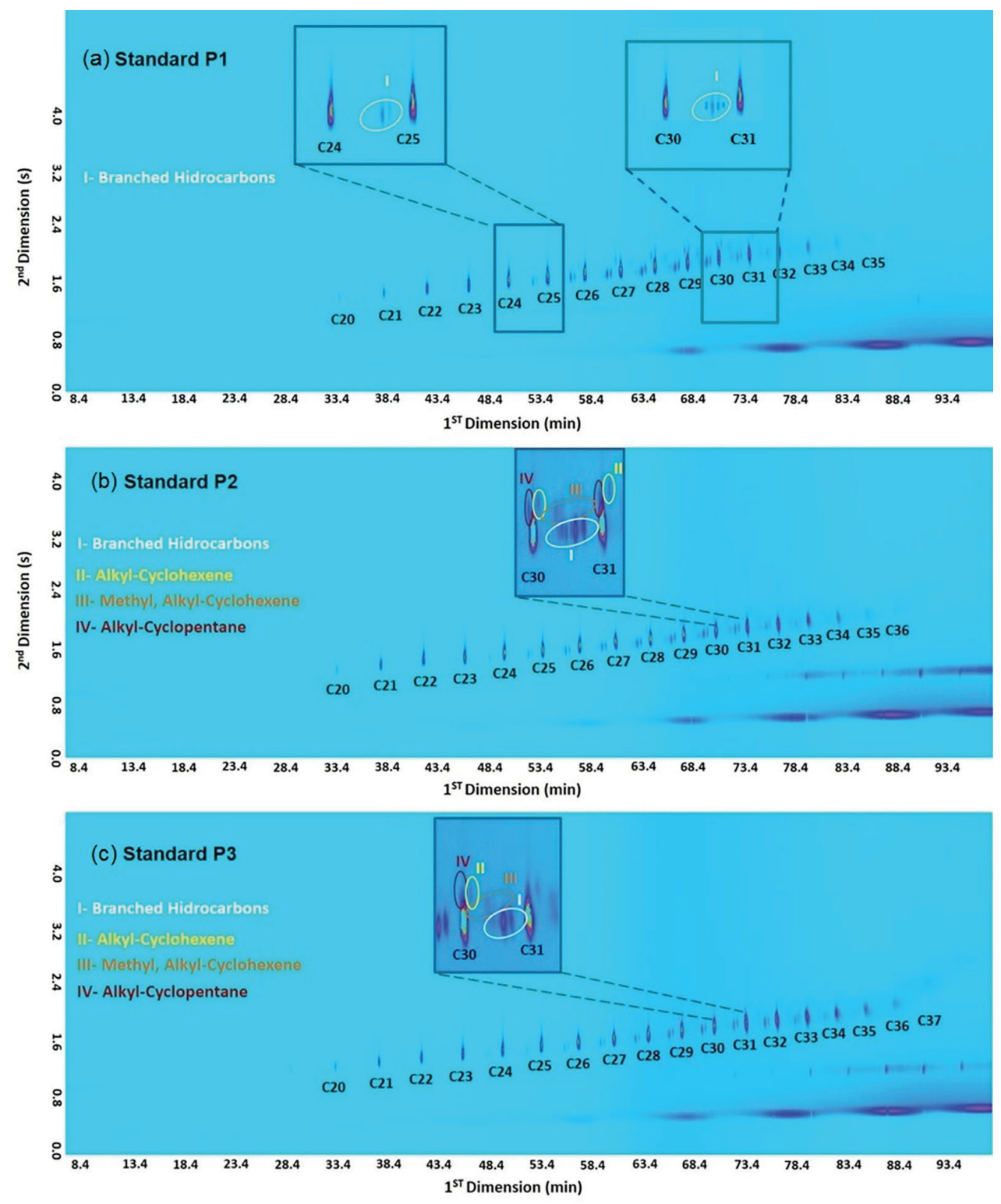

Figure 5. GC $\times$ GC/q-MS chromatograms of three paraffin standards (samples P1-P3).

Table 4. Values of theoretical mass, experimental mass, mass error, molecular formula and DBE for the PAH standards analyzed by APCI(+)FT-ICR MS

\begin{tabular}{|c|c|c|c|c|c|}
\hline aAH standard & Measured $\mathrm{m} / \mathrm{z}$ & Theoretical $\mathrm{m} / \mathrm{z}$ & Error / ppm & Molecular formula & ${ }^{\mathrm{b}} \mathrm{DBE}$ \\
\hline A1 & 475.16664 & 475.16523 & 2.67 & {$\left[\mathrm{C}_{30} \mathrm{H}_{22} \mathrm{~N}_{2} \mathrm{O}_{4}+\mathrm{H}\right]^{+}$} & 21 \\
\hline \multirow[t]{3}{*}{$\mathrm{A} 2$} & 253.10064 & 253.10118 & 2.13 & {$\left[\mathrm{C}_{20} \mathrm{H}_{12}+\mathrm{H}\right]^{+}$} & 15 \\
\hline & 269.13244 & 269.13248 & 0.15 & {$\left[\mathrm{C}_{21} \mathrm{H}_{16}+\mathrm{H}\right]^{+}$} & 14 \\
\hline & 303.11635 & 303.11683 & 1.58 & {$\left[\mathrm{C}_{24} \mathrm{H}_{14}+\mathrm{H}\right]^{+}$} & 18 \\
\hline A3 & 229.10077 & 229.10118 & 1.79 & {$\left[\mathrm{C}_{18} \mathrm{H}_{12}+\mathrm{H}\right]^{+}$} & 13 \\
\hline A4 & 301.10045 & 301.10118 & 2.42 & {$\left[\mathrm{C}_{24} \mathrm{H}_{12}+\mathrm{H}\right]^{+}$} & 19 \\
\hline A5 & 531.22862 & 531.22783 & 1.49 & {$\left[\mathrm{C}_{34} \mathrm{H}_{30} \mathrm{~N}_{2} \mathrm{O}_{4}+\mathrm{H}\right]^{+}$} & 21 \\
\hline \multirow[t]{3}{*}{ A6 } & 229.10077 & 229.10118 & 1.79 & {$\left[\mathrm{C}_{18} \mathrm{H}_{12}+\mathrm{H}\right]^{+}$} & 13 \\
\hline & 253.10072 & 253.10118 & 2.10 & {$\left[\mathrm{C}_{20} \mathrm{H}_{12}+\mathrm{H}\right]^{+}$} & 15 \\
\hline & 309.16345 & 309.16378 & 1.07 & {$\left[\mathrm{C}_{24} \mathrm{H}_{20}+\mathrm{H}\right]^{+}$} & 15 \\
\hline
\end{tabular}

aPAH: polyaromatic hydrocarbon; 'DBE: double bond equivalent. 
the standards $\mathrm{A} 2$ and A6, a mixture of PAHs molecules was detected. They were $\left[\mathrm{C}_{20} \mathrm{H}_{12}+\mathrm{H}\right]^{+},\left[\mathrm{C}_{21} \mathrm{H}_{16}+\mathrm{H}\right]^{+}$, and $\left[\mathrm{C}_{24} \mathrm{H}_{14}+\mathrm{H}\right]^{+}$ions (Figure S5b, SI section) and $\left[\mathrm{C}_{18} \mathrm{H}_{12}+\mathrm{H}\right]^{+},\left[\mathrm{C}_{20} \mathrm{H}_{12}+\mathrm{H}\right]^{+}$, and $\left[\mathrm{C}_{24} \mathrm{H}_{20}+\mathrm{H}\right]^{+}$ions (Figure S5f, SI section, and Table 4), respectively.

In order to provide a comparison of the fragmentation standards of PAHs with acyclic and cyclic paraffins, CID experiments were performed for two $\mathrm{PAH}$ molecules: coronene (standard A4, m/z 301.10045, $\left[\mathrm{C}_{24} \mathrm{H}_{12}+\mathrm{H}\right]^{+}$) and benzoantracene (standard A3, $\mathrm{m} / \mathrm{z}, 229.10077$, $\left.\left[\mathrm{C}_{18} \mathrm{H}_{12}+\mathrm{H}\right]^{+}\right)$. APCI $(+)$MS/MS spectra are shown in Figures S6a-S6b (SI section), where, in both cases, mainly the elimination of a hydrogen radical, $1 \mathrm{Da}(\bullet \mathrm{H})$, was observed. This fragmentation profile remained constant independent of the applied collision energy (ranging from 0 to $30 \mathrm{eV}$ ). The increase in the collision energy caused only the reduction of the total ion count as well as the reduction of intensity of the parent ions, $m / z 301$ and 229.

The efficiency of ionization of APCI(+) using isooctane as ionizing reagent was tested for mixtures between a PAH standard and $n$-paraffins. To verify this behavior, the paraffin standard P4 was doped with coronene $\left([\mathrm{M}+\mathrm{H}]^{+}\right.$cation of $\mathrm{m} / z$ 301) at concentrations from 2.5 to $25 \mu \mathrm{g} \mathrm{mL} \mathrm{m}^{-1}$. Figure 6 shows the $\mathrm{APCI}(+)$ FT-ICR mass spectra obtained for the coronene/paraffin blends, where it is clearly evident that the paraffin-related Gaussian profiles were progressively suppressed with the increase in the coronene concentration $(\mathrm{m} / \mathrm{z} 301)$. A maximum suppression was observed at $25 \mu \mathrm{g} \mathrm{mL}-1$ of coronene (Figure 6a). This behavior could also be observed from the DBE distribution histograms versus intensity (Figure $6 \mathrm{~b}$ ), where at low coronene concentrations $\left(<15 \mu \mathrm{g} \mathrm{mL}^{-1}\right)$, there was a predominance of HC compounds of DBE $=0-8$, comprising $n$-paraffins/ isoparaffins $(\mathrm{DBE}=0)$ and cyclic paraffins (cycloalkanes and naphthenes, $\mathrm{DBE} \geq 1$ ). When coronene was added at concentrations of 15 and $25 \mu \mathrm{g} \mathrm{mL} \mathrm{L}^{-1}$, the suppression of cyclic paraffins, compounds with $0<\mathrm{DBE}<9$, was first observed, followed by the suppression of $n$-paraffins $(\mathrm{DBE}=0)$, which corresponded to the dominant species. Consequently, the coronene molecule was primarily ionized, giving rise to the peak with $\mathrm{DBE}=19$.

\section{Saturated fractions analysis}

APCI(+)FT-ICR MS was also applied for two saturated fractions (named fractions $S_{A}$ and $S_{B}$, Figures $7 a-7 b$ ), and the results were compared to $\mathrm{GC} \times \mathrm{GC} / \mathrm{q}-\mathrm{MS}$ data (Figure 8). Saturated fractions $\mathrm{S}_{\mathrm{A}}$ and $\mathrm{S}_{\mathrm{B}}$, obtained by the SAP method, showed Gaussian profiles of $m / z, 200-1100$ with $\mathrm{M}_{\mathrm{w}}=615$ and 631, respectively (Figures $7 \mathrm{a}-7 \mathrm{~b}$ ).
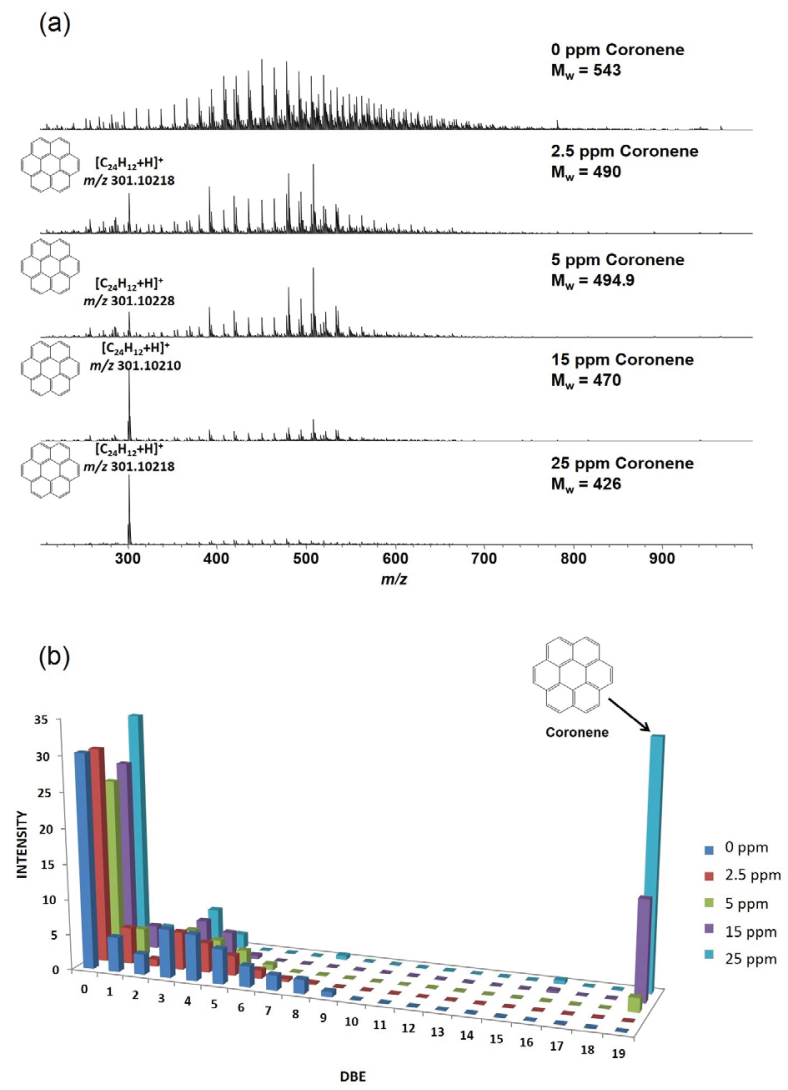

Figure 6. (a) APCI(+)FT-ICR mass spectra of coronene/paraffin blends. (b) DBE distribution for the $\mathrm{HC}[\mathrm{H}]$ class.

Saturated fractions displayed complex chemical profiles when compared to the data shown in Figure 1. Note a greater predominance of cyclic $\mathrm{HC}$ molecules and possibly traces of PAHs containing $\mathrm{CNs}$ from $\mathrm{C}_{15}$ to $\mathrm{C}_{78}$ and DBE 1 to 13 (Figures 7c-7d).

This complex chemical profile was also reflected in the two-dimensional GC data, where detected compounds corresponding to linear HCs; branched HCs; mono-, bi-, tri-, tetra- and penta-cyclic HCs; and PAHs (Figures 8a-8b and Figure S7, SI section). A higher concentration of cyclic paraffin was clearly seen in fraction $S_{B}$, as well as the presence of PAHs (in low abundance, Figure 8b). As a consequence, the ionization of $n$-paraffins via $\mathrm{APCI}(+) \mathrm{MS}$ was affected (Figure 7b). As discussed earlier, PAHs suppressed the ionization of paraffins. On the other hand, for fraction $\mathrm{S}_{\mathrm{A}}$ (Figure 7a), $n$-paraffins $\left(\mathrm{CNs}\right.$ of $\mathrm{C}_{15}-\mathrm{C}_{65}$ ) were easily ionized.

\section{Conclusions}

Hydrocarbons from non-polar fraction of crude oil can be easily assessed by APCI(+)FT-ICR MS. The distribution of carbon number among paraffin samples were in good agreement with HTGC data. $\mathrm{APCI}(+)-\mathrm{MS}$ was shown to be 

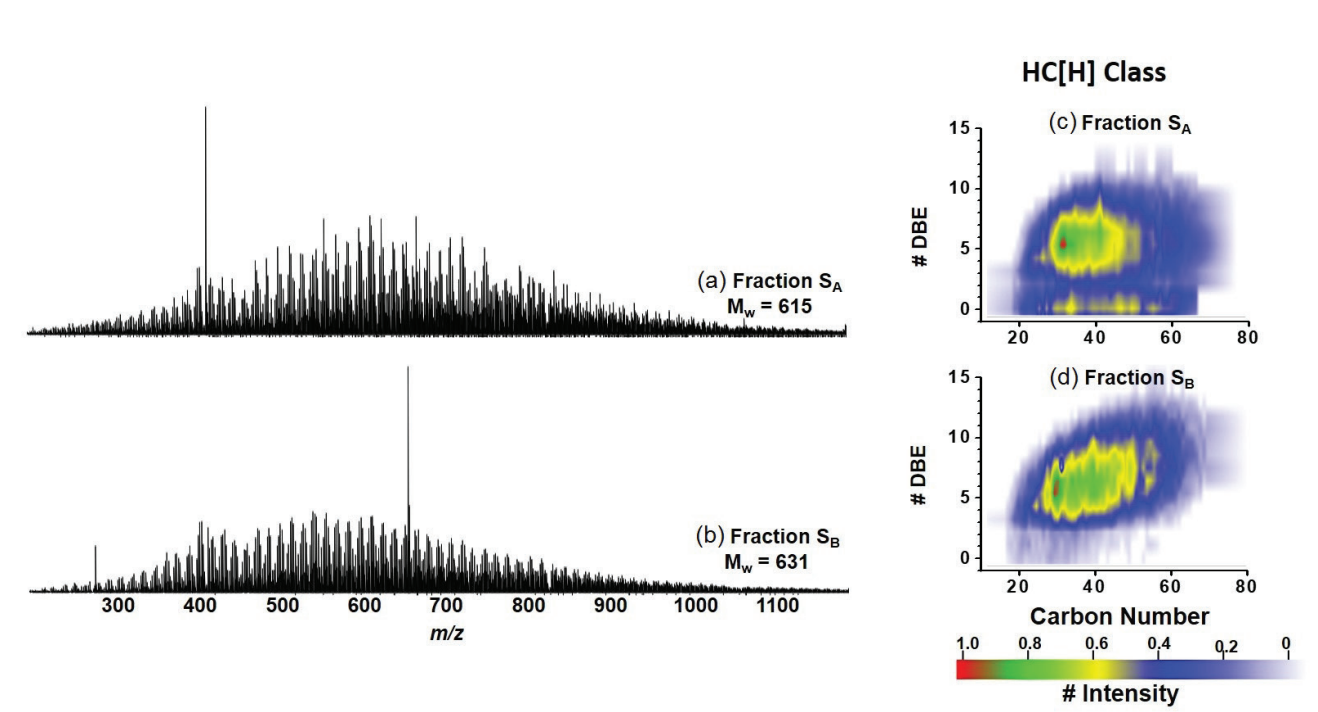

Figure 7. $(\mathrm{a}, \mathrm{b}) \mathrm{APCI}(+)$ FT-ICR mass spectra of two saturated fractions $\left(\mathrm{S}_{\mathrm{A}}\right.$ and $\left.\mathrm{S}_{\mathrm{B}}\right)$ of Brazilian crude oils and $(\mathrm{c}, \mathrm{d})$ their respective DBE versus $\mathrm{CN}$ plots.

(a) Fraction $\mathrm{S}_{\mathrm{A}}$

A- $\boldsymbol{n}$-paraffins/ Isoparaffins; B- Monocyclic; C-Bicyclic; D-Tricyclic; E- Tetracyclic; F- Pentacyclic;

G- monodimensional chromatogram;

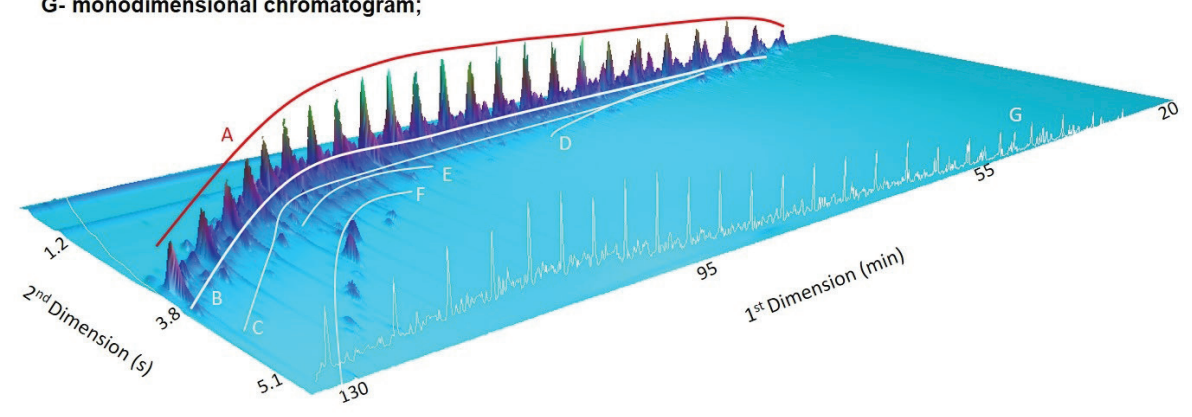

(b) Fraction $S_{B}$

A- $n$-paraffins/ Isoparaffins; B- Monocyclic; C- Bicyclic; D-Tricyclic; E- Pentacyclic; F- Tetracyclic; G- Aromatics

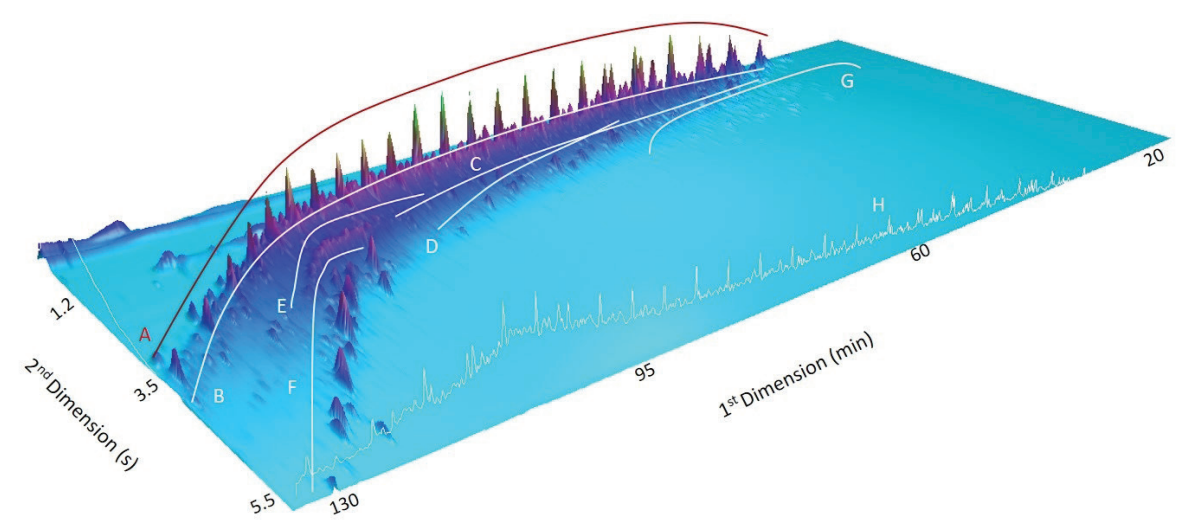

Figure 8. GC $\times \mathrm{GC} / \mathrm{q}-\mathrm{MS}$ of the two saturated fractions: (a) $\mathrm{S}_{\mathrm{A}}$ and (b) $\mathrm{S}_{\mathrm{B}}$. In both samples, the presence of $n$-paraffins/isoparaffins and cyclic paraffins with $\mathrm{DBE}=1-5$ (mono, by, tri, tetra and pentacyclic paraffin) was observed. PAHs were detected only in fraction $\mathrm{S}_{\mathrm{B}}$ in low abundance.

able to assess paraffin molecules with $\mathrm{M}_{\mathrm{w}} \mathrm{s}$ of ca. $1200 \mathrm{Da}$, discriminating carbon numbers from $\mathrm{C}_{16}$ to $\mathrm{C}_{80}$.

A good agreement was observed when $\mathrm{APCI}(+)-\mathrm{MS}$ and ${ }^{1} \mathrm{H}$ NMR data were compared. The $\mathrm{H}_{\beta}$ contents could be directly associated to $\mathrm{M}_{\mathrm{w}} \mathrm{s}$ that increased in the following order: standard P1 $\left(\mathrm{M}_{\mathrm{w}}=431 \mathrm{Da}\right)<$ standard P2 $\left(\mathrm{M}_{\mathrm{w}}=444 \mathrm{Da}\right)<$ standard $\mathrm{P} 4\left(\mathrm{M}_{\mathrm{w}}=551 \mathrm{Da}\right)<$ standard $\mathrm{P} 3$ $\left(\mathrm{M}_{\mathrm{w}}=571 \mathrm{Da}\right)<\operatorname{standard} \mathrm{P} 5\left(\mathrm{M}_{\mathrm{w}}=662 \mathrm{Da}\right)$. 
$\mathrm{GC} \times \mathrm{GC} / \mathrm{q}-\mathrm{MS}$ data from paraffin standards presented good agreement with the DBE versus $\mathrm{CN}$ plots provided by $\mathrm{APCI}(+)$ FT-ICR MS data. Both $\mathrm{GC} \times \mathrm{GC} / \mathrm{q}-\mathrm{MS}$ and APCI(+)FT-ICR MS indicated the presence of cyclic paraffin in two paraffin standard samples and saturated fractions obtained from SAP method. The presence of $\mathrm{PAH}$ at a concentration higher than $25 \mathrm{ppm}$ completely suppressed the ionization of paraffins.

APCI(+)FT-ICR MS using isooctane as reagent gas can be easily used to assess the non-polar information of crude oil samples, so far assessed mostly by electron ionization mass spectrometry or chromatographic techniques. Therefore, as demonstrated here, even in the presence of low proportions of PAHs, paraffin can be ionized using APCI(+)MS.

\section{Supplementary Information}

Chromatograms from the HTGC analysis of paraffin standard; chemical profile of $\mathrm{CN}$ distribution of paraffin standard; ${ }^{1} \mathrm{H}$ NMR spectra of paraffin standard; ${ }^{13} \mathrm{C}$ NMR spectra of paraffin standard; APCI(+)FT-ICR mass spectra for PAH standards; APCI(+)MS/MS spectra of two PAH standards; and percentage in weight (wt.\%) of $\mathrm{HCs}$ identified in the two saturated fractions by GC $\times$ GC-MS, are available free of charge at http://jbcs.sbq.org.br as PDF file.

\section{Acknowledgments}

The authors are grateful to CNPq, FAPES and CAPES for financing the research. The authors also thank the Núcleo de Competências em Química do Petróleo (UFES), coordinated by Prof Dr Eustaquio V. R. Castro, for the FT-ICR MS, NMR, HTGC-FID and GC $\times$ GC/q-MS analyses as well as to LabPetro for the chemical characterization of the crude oils, and PETROBRAS for providing the crude oil samples.

\section{References}

1. Pudenzi, M. A.; Santos, J. M.; Wisniewski Jr., A.; Eberlin, M. N.; Energy Fuels 2018, 32, 1038.

2. Angolini, C. F.; Pudenzi, M. A.; Batezelli, A.; Eberlin, M. N.; Encyclopedia of Analytical Chemistry: Applications, Theory and Instrumentation, $1^{\text {st }}$ ed.; John Wiley \& Sons: New York, 2017.

3. Marshall, A. G.; Rodgers, R. P.; Proc. Natl. Acad. Sci. U. S. A. 2008, 105, 18090.

4. Zhou, X.; Zhang, Y.; Zhao, S.; Chung, K. H.; Xu, C.; Shi, Q.; Energy Fuels 2014, 28, 417.
5. Zhou, X.; Shi, Q.; Zhang, Y.; Zhao, S.; Zhang, R.; Chung, K. H.; Xu, C.; Anal. Chem. 2012, 84, 3192.

6. Campbell, J. L.; Crawford, K. E.; Kenttämaa, H. I.; Anal. Chem. 2004, 76, 959.

7. Nyadong, L.; Quinn, J. P.; Hsu, C. S.; Hendrickson, C. L.; Rodgers, R. P.; Marshall, A. G.; Anal. Chem. 2012, 84, 7131.

8. Vaz, B. G.; Abdelnur, P. V.; Rocha, W. F. C.; Gomes, A. O.; Pereira, R. C. L.; Energy Fuels 2013, 27, 1873.

9. Klein, G. C.; Kim, S.; Rodgers, R. P.; Marshall, A. G.; Yen, A.; Energy Fuels 2006, 20, 1973.

10. McKenna, A. M.; Marshall, A. G.; Rodgers, R. P.; Energy Fuels 2013, 27, 1257.

11. Purcell, J. M.; Merdrignac, I.; Rodgers, R. P.; Marshall, A. G.; Gauthier, T.; Guibard, I.; Energy Fuels 2010, 24, 2257.

12. Benigni, P.; DeBord, J. D.; Thompson, C.; Gardinali, P.; Fernandez-Lima, F.; Energy Fuels 2016, 30, 196.

13. Castellanos, A.; Benigni, P.; Hernandez, D. R.; DeBord, J. D.; Ridgeway, M. E.; Park, M. A.; Fernandez-Lima, F.; Anal. Methods 2014, 6, 9328.

14. Lorente, E.; Berrueco, C.; Herod, A. A.; Millan, M.; Kandiyoti, R.; Rapid Commun. Mass Spectrom. 2012, 26, 1581.

15. Gao, J.; Owen, B. C.; Borton II, D. J.; Jin, Z.; Kenttämaa, H. I.; J. Am. Soc. Mass Spectrom. 2012, 23, 816.

16. Tose, L. V.; Cardoso, F. M. R.; Fleming, F. P.; Vicente, M. A.; Silva, S. R. C.; Aquije, G. M. F. V.; Vaz, B. G.; Romão, W.; Fuel 2015, 153, 346.

17. Dias, H. P.; Dixini, P. V.; Almeida, L. C. P.; Vanini, G.; Castro, E. V. R.; Aquije, G. M. F. V.; Gomes, A. O.; Moura, R. R.; Lacerda Jr., V.; Vaz, B. G.; Romão, W.; Fuel 2015, 139, 328.

18. Freitas, S.; Malacarne, M. M.; Romão, W.; Dalmaschio, G. P.; Castro, E. V. R.; Celante V. G.; Freitas, M. B. J. G.; Fuel 2013, $104,656$.

19. Hourani, N.; Muller, H.; Adam, F. M.; Panda, S. K.; Witt, M.; Al-Hajji, A. A.; Sarathy, S. M.; Energy Fuels 2015, 29, 2962.

20. Smit, E.; Rüger, C. P.; Sklorz, M.; De Goede, S.; Zimmermann, R.; Rohwer, E. R.; Energy Fuels 2015, 29, 5554.

21. Cho, Y.; Witt, M.; Kim, Y. H.; Kim, S.; Anal. Chem. 2012, 84, 8587.

22. Lydon, C.; DeBord, J. D.; Fernandez-Lima, F.; Prepr. - Am. Chem. Soc., Div. Energy Fuels 2013, 58, 949.

23. Romão, W.; Tose, L. V.; Vaz, B. G.; Sama, S. G.; Lobinski, R.; Giusti, P.; Carrier, H.; Bouyssiere, B.; J. Am. Soc. Mass Spectrom. 2016, 27, 182.

24. Adermann, N.; Boggiano, J.; Composer, version 1.5.3; Sierra Analytics, Pasadena, CA, USA, 2016.

25. Schmidt, E. M.; Pudenzi, M. A.; Santos, J. M.; Angolini, C. F. F.; Pereira, R. C. L.; Rocha, Y. S.; Denisov, E.; Damoc, E.; Makarov, A.; Eberlin, M. N.; RSC Adv. 2018, 8, 6183.

26. ASTM D7169-05: Standard Test Method for Boiling Point Distribution of Samples with Residues such as Crude Oils and 
Atmospheric and Vacuum Residues by High Temperature Gas Chromatography; ASTM International: West Conshohocken, Pennsylvania, 2005.

27. Oliveira, E. C. S.; Neto, A. C.; Lacerda Jr., V.; Castro, E. V. R.; de Menezes, S. M. C.; Fuel 2014, 117, 146.

28. Wu, C.; Qian, K.; Nefliu, M.; Cooks, R. G.; J. Am. Soc. Mass Spectrom. 2010, 21, 261.

29. Filgueiras, P. R.; Portela, N. A.; Silva, S. R. C.; Castro, E. V. R.; Oliveira, L. M. S. L.; Dias, J. C. M.; Neto, A. C.; Romão, W.; Poppi, R. J.; Energy Fuels 2016, 30, 1972.

30. Cookson, D. J.; Smith, B. E.; Anal. Chem. 1985, 57, 864.

31. Speight, R. J.; Rourke, J. P.; Wong, A.; Barrow, N. S.; Ellis, P.; Bishop, P. T.; Smith, M. E.; Solid State Nucl. Magn. Reson. 2011, 39, 58.

32. Sperber, O.; Kaminsky, W.; Geißler, A.; Pet. Sci. Technol. 2005, 23,47 .
33. Alcazar-Vara, L. A.; Garcia-Martinez, J. Á.; BuenrostroGonzalez, E.; Fuel 2012, 93, 200.

34. Espada, J. J.; Coutinho, J. A.; Peña, J. L.; Energy Fuels 2010 , $21,1837$.

35. Deursen, Mv.; Beens, J.; Reijenga, J.; Lipman, P.; Cramers, C.; J. High Resolut. Chromatogr. 2000, 23, 507.

36. Martos, C.; Coto, B.; Espada, J. J.; Robustillo, M. D.; Gómez, S.; Peña, J. L.; Energy Fuels 2008, 22, 708.

37. Coto, B.; Martos, C.; Espada, J. J.; Robustillo, M. D.; Peña, J. L.; Fuel 2010, 89, 1087.

38. Welthagen, W.; Schnelle-Kreis, J.; Zimmermann, R.; J. Chromatogr. A 2003, 1019, 233.

Submitted: August 28, 2018 Published online: December 18, 2018 